\title{
Postoperative opioid consumption after spine surgery: 24 hours or midnight to midnight? An infographic
}

\author{
Rajnish K Gupta (1) , ${ }^{1}$ Eric S Schwenk (i) ${ }^{2}$
}

\section{SUMMARY}

While postoperative opioid consumption is commonly reported in pain studies, there is no standard definition of the intervals over which it is reported. In the article by Lam et al, ${ }^{1}$ the authors found that $43.8 \%$ of reported opioid consumption would be missed if postoperative day 1 begins at midnight after surgery. The authors proposed that opioid consumption be measured in 24-hour intervals beginning at anesthesia stop time to allow for consistent comparisons across studies.
${ }^{1}$ Anesthesiology, Vanderbilt University Medical Center, Nashville, Tennessee, USA

${ }^{2}$ Anesthesiology, Sidney Kimmel Medical College,

Thomas Jefferson University, Philadelphia, Pennsylvania, USA

Correspondence to Dr Eric S Schwenk, Anesthesiology, Sidney Kimmel Medical College at Thomas Jefferson University, Philadelphia, PA 19107, USA; Eric.Schwenk@jefferson.edu

Twitter Rajnish K Gupta @dr_rajgupta and Eric S Schwenk@ESchwenkMD

Acknowledgements The authors would like to acknowledge Jim Snively, artist, of Pittsburgh, Pennsylvania, for creation of this infographic.

\section{Which opioid outcomes matter?}

We don't have a standard definition of postoperative opioid consumption.

24i: Opioid consumption measured in 24-hour intervals after anesthesia stop time.
POD@MN: PODO is from end of surgery to midnight (MN). Each subsequent POD is MN to MN.

Contributors Both authors contributed equally to this manuscript.

Funding The authors have not declared a specific grant for this research from any funding agency in the public, commercial or not-for-profit sectors.

Competing interests None declared.

Patient consent for publication Not required.

Provenance and peer review Commissioned; internally peer reviewed.

(c) American Society of Regional Anesthesia \& Pain Medicine 2021. No commercial re-use. See rights and permissions. Published by BMJ.

\section{(D) Check for updates}

To cite Gupta RK, Schwenk ES. Reg Anesth Pain Med 2021;46:822.

Received 8 April 2021

Accepted 8 April 2021

Published Online First 14 April 2021

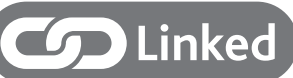

- http://dx.doi.org/10.1136/rapm-2020-102462

Reg Anesth Pain Med 2021;46:822.

doi:10.1136/rapm-2021-102761

ORCID iDs

Rajnish K Gupta http://orcid.org/0000-0003-3401-

4737

Eric S Schwenk http://orcid.org/0000-0003-3464-4149

\section{REFERENCE}

1 Lam S, Veselis R, Malhotra V. Postoperative opioid consumption after spine surgery: 24 hours or midnight to midnight? Reg Anesth Pain Med 2021;46:823-4. 